\title{
Dimerization and enzymatic activity of fungal I $7 \beta$-hydroxysteroid dehydrogenase from the short-chain dehydrogenase/reductase superfamily
}

\author{
Katja Kristan*1, Dominga Deluca ${ }^{2}$, Jerzy Adamski ${ }^{2}$, Jure Stojan ${ }^{1}$ and \\ Tea Lanišnik Rižner*1
}

Address: ${ }^{1}$ Institute of Biochemistry, Medical Faculty, University of Ljubljana, Vrazov trg 2, 1000 Ljubljana, Slovenia and ${ }^{2}$ GSF-National Research Centre for Environment and Health, Institute of Experimental Genetics, Genome Analysis Center, Ingolstädter Landstraße 1, 85764 Neuherberg, Germany

Email: Katja Kristan* - katja.kristan@mf.uni-lj.si; Dominga Deluca - deluca@gsf.de; Jerzy Adamski - adamski@gsf.de; Jure Stojan - jurij.stojan@mf.uni-lj.si; Tea Lanišnik Rižner* - tea.lanisnik-rizner@mf.uni-lj.si

* Corresponding authors

Published: 16 December 2005

BMC Biochemistry 2005, 6:28 doi:10.1186/|47|-209/-6-28
Received: 19 July 2005

Accepted: 16 December 2005

This article is available from: http://www.biomedcentral.com/I47I-209I/6/28

(C) 2005 Kristan et al; licensee BioMed Central Ltd.

This is an Open Access article distributed under the terms of the Creative Commons Attribution License (http://creativecommons.org/licenses/by/2.0), which permits unrestricted use, distribution, and reproduction in any medium, provided the original work is properly cited.

\begin{abstract}
Background: 17 $\beta$-hydroxysteroid dehydrogenase from the fungus Cochliobolus lunatus (17 $\beta$ HSDcl) is a member of the short-chain dehydrogenase/reductase (SDR) superfamily. SDR proteins usually function as dimers or tetramers and $17 \beta-\mathrm{HSDcl}$ is also a homodimer under native conditions.
\end{abstract}

Results: We have investigated here which secondary structure elements are involved in the dimerization of $17 \beta-\mathrm{HSDcl}$ and examined the importance of dimerization for the enzyme activity. Sequence similarity with trihydroxynaphthalene reductase from Magnaporthe grisea indicated that ArgI29 and HisIII from the $\alpha$ E-helices interact with the Aspl2I, Glul I7 and Aspl87 residues from the $\alpha E$ and $\alpha F$-helices of the neighbouring subunit. The ArgI 29Asp and His I I Leu mutations

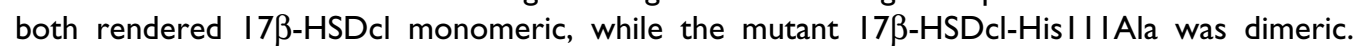
Circular dichroism spectroscopy analysis confirmed the conservation of the secondary structure in both monomers. The three mutant proteins all bound coenzyme, as shown by fluorescence quenching in the presence of NADP ${ }^{+}$, but both monomers showed no enzymatic activity.

Conclusion: We have shown by site-directed mutagenesis and structure/function analysis that $17 \beta-H S D c l$ dimerization involves the $\alpha E$ and $\alpha \mathrm{F}$ helices of both subunits. Neighbouring subunits are connected through hydrophobic interactions, $\mathrm{H}$-bonds and salt bridges involving amino acid residues HisIII and ArgI29. Since the substitutions of these two amino acid residues lead to inactive monomers with conserved secondary structure, we suggest dimerization is a prerequisite for catalysis. A detailed understanding of this dimerization could lead to the development of compounds that will specifically prevent dimerization, thereby serving as a new type of inhibitor.

\section{Background}

Members of the short-chain dehydrogenase/reductase
(SDR) superfamily are non-metallo enzymes with molecular masses between 25 and $35 \mathrm{kDa}$ that function in the 


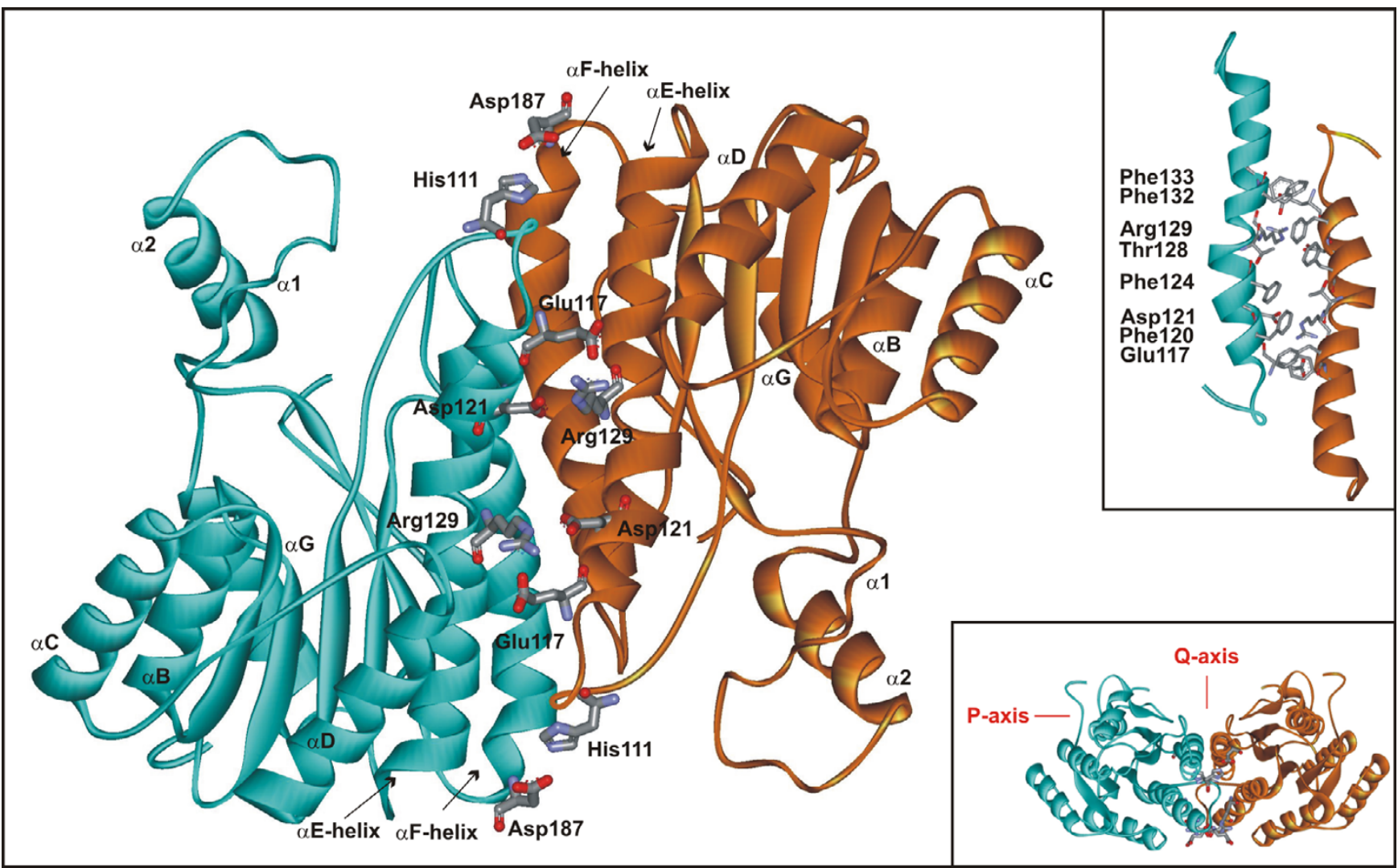

Figure I

Ribbon diagram showing the dimerization of I 7 $\beta-H S D c l$ across the Q-axis. The amino acids crucial for the dimerization across the $\mathrm{Q}$-axes are depicted. The enlarged subunit interactions at the $\alpha \mathrm{E}-\alpha \mathrm{E}$ contact region are also shown (inset).

form of dimers or tetramers [1]. The crystal structures of several SDR proteins have revealed that the protein fold is highly conserved within this superfamily [2]. The SDR tetramers display 222 symmetry with two different interfaces between their 4 subunits, described by three orthogonal molecular axes, called P, Q and R [3]. The most extensive contacts are those spanning the $\mathrm{Q}$-axis and involve two helices, $\alpha \mathrm{E}$ and $\alpha \mathrm{F}$. In most homodimeric SDRs for which the structure is known, dimerization also occurs across this interface. So far, only one SDR protein, the $3 \alpha$-hydroxysteroid dehydrogenase/carbonyl reductase (3 $\alpha$-HSD/CR) from Comamonas testosteroni (pdb code 1FK8), has been shown to differ in its mode of dimerization. In this case, dimerization takes place across the Paxis interface, formed mainly by the $\alpha \mathrm{G}$ helices and by interactions between the $\beta G$ strands of two neighbouring subunits $[4,5]$. To date, only two monomeric structures, those of porcine testicular carbonyl reductase (PTCR) (pdb code 1N5D) and human carbonyl reductase (CBR1) (pdb code 1WMA), are known within the SDR superfamily $[6,7]$.
Although there are about three thousand members of the SDR superfamily in the species studied [8], 17 $\beta$-HSD from the fungus Cochliobolus lunatus (17 $\beta$-HSDcl) [9] is currently the only fungal HSD member that has been characterized. The enzyme has been purified, and also cloned and expressed in E. coli $[9,10]$. Under native conditions, both recombinant [10] and natural [9] 17ß-HSDcl form dimers. $17 \beta$-HSDcl is homologous to fungal reductases: to versicolorin reductases from Aspergillus parasiticus and Emericella nidulans, which are involved in aflatoxin biosynthesis; and to the 1,3,8-trihydroxynaphthalene reductases and 1,3,6,8-tetrahydroxynaphthalene reductases (3HNR, 4HNR) from Magnaporthe grisea, Ophiostoma floccosum and other fungi, which are involved in melanin biosynthesis [11]. 3HNR and 4HNR catalyze an essential reaction in the biosynthesis of melanin, a virulence factor of phyto-pathogenic fungi, as well as of fungi pathogenic to humans [12-15]. These enzymes are the biochemical targets of several commercially important fungicides that are used to prevent blast disease in rice plants $[15,16]$. The study of the fungal $17 \beta$-HSD will, therefore, contribute to 
Table I: Comparisons of the amino acids potentially involved in dimerization across the $Q$ - and $P$-axis interface in $3 H N R$ and I7 $\beta$ HSDcl.

\begin{tabular}{|c|c|c|c|}
\hline \multicolumn{2}{|c|}{ Q-axis interface } & \multicolumn{2}{|c|}{ P-axis interface } \\
\hline 3HNR & I7 $\beta$-HSDcl & 3HNR & I7 $\beta$-HSDcl \\
\hline & rophobic interactions & \multicolumn{2}{|c|}{ hydrophobic interactions } \\
\hline Phel31 & Phel 20 & Phe26I & Phe249 \\
\hline Phel35 & Phel24 & Trp269 & Trp257 \\
\hline Phel43 & Phel 32 & \multicolumn{2}{|c|}{ salt bridges } \\
\hline Phel44 & Phel 33 & Asp266-Arg52 & \\
\hline Phel88 & Phel77 & Asp278-Lys273 & Asp266-Lys26 \\
\hline \multicolumn{4}{|c|}{ salt bridges/H-bonds } \\
\hline Arg I 40-Asp I 32 & Arg I29-Asp I I/Glul I7 & & \\
\hline His I 22-Asp I 98 & His III-Aspl87 & & \\
\hline
\end{tabular}

a better understanding of the functionality of these homologous fungal enzymes that are targets for the design of novel antifungal agents. As fungal $17 \beta-\mathrm{HSD}$ exhibits about $30 \%$ amino acid identity to human $17 \beta$ HSD types 4 and 8 [11], this could also lead to an understanding of the mechanisms of catalysis in human HSDs, which are implicated in the development of steroiddependent forms of cancer, polycystic kidney disease, regulation of blood pressure, Alzheimer's disease and obesity [17-23]. A detailed understanding of the individual amino acids that are important for dimerization could enable the design of compounds that would specifically prevent dimerization, and consequently the enzyme activity of the SDR proteins, and should therefore serve as new types of drugs [24].

Dimerization of the SDR proteins has already been studied in Drosophila alcohol dehydrogenase (ADH), where ethyl methanesulphonate-induced null mutants were prepared and examined. Among the mutants studied, the inactive mutant Ala159Thr did not form a stable homodimer, suggesting that Ala159 is important for hydrophobic interactions that stabilize the ADH dimer [25]. Dimerization has also been studied in human $17 \beta$ HSD type 1 , an enzyme that has a high affinity for dimer formation (dimer dissociation constant $K_{d d} \leq 5 \mathrm{pM}$ ) and consequently exists only as a dimer in vitro [26]. The $17 \beta$ HSD type 1 mutations Leu111Glu/Val113Phe and Ala170Glu+Phe172 abolished its activity and changed the folding of the enzyme. Both mutated proteins formed aggregates with apparent molecular weights of more than $300 \mathrm{kDa}$; monomeric or dimeric forms of the enzyme were not seen [26]. Based on a comparison of the structures of fungal $17 \beta-\mathrm{HSD}[27,28]$ (Figure 1) and the homotetrameric 3HNR from Magnaporthe grisea ( $\mathrm{pdb}$ code $1 \mathrm{YBV}$ ) [12], we investigated the dimerization of $17 \beta$ HSDcl by site-directed mutagenesis. We have identified the secondary structure elements and the amino acids essential for dimerization and have demonstrated the relationship between dimerization and enzyme activity.

\section{Results}

Structural comparisons indicate that His I I I and Arg I 29 are involved in dimerization

The sequence alignments and structural comparison of the three-dimensional models of fungal $17 \beta$-HSD [27], supported by our preliminary crystallographic data [28], with the homologous 3HNR [pdb code 1YBV], aligned without gaps between residue number 15 to 222 in $17 \beta$ HSDcl and residues 26 to 233 in 3HNR (60\% of identical amino acids), identified strong hydrophobic and aromatic interactions across the Q-axis (Phe120, Phe124, Phe132, Phe133, Phe177) and potential salt bridges/Hbonds between the $\alpha \mathrm{E}$ and $\alpha \mathrm{F}$ helices of the two subunits, all of which may stabilize dimerization (Table 1, Figure 1). One salt bridge can be formed between $\operatorname{Arg} 129$ and Glu117 and/or Asp121 from the $\alpha$ E helices, while His111, which is positioned in front of the $\alpha \mathrm{E}$ helix, can form an H-bond with Asp187 from the $\alpha$ F helix (Table 1, Figure 1 ). The interactions between the P-axis-related subunits are not so extensive and the surface amino acids are less hydrophobic than those of tetrameric 3HNR (Table 1). To test our hypothesis that dimerization takes place across the Q-axis, the His111Ala, His111Leu and Arg129Asp mutants were prepared with the aim of selectively omitting one H-bond (His111Ala and His111Leu) and of introducing electrostatic repulsion between the monomers (Arg129Asp).

\section{The His I I Leu and Arg I29Asp mutations each result in monomeric proteins}

The purities of the expressed proteins were checked by SDS-PAGE, where all of the proteins appeared as bands with the expected molecular mass of $28 \mathrm{kDa}$ and were approx. 90\% homogenous. The solution molecular mass was determined by gel filtration and by non-denaturing 

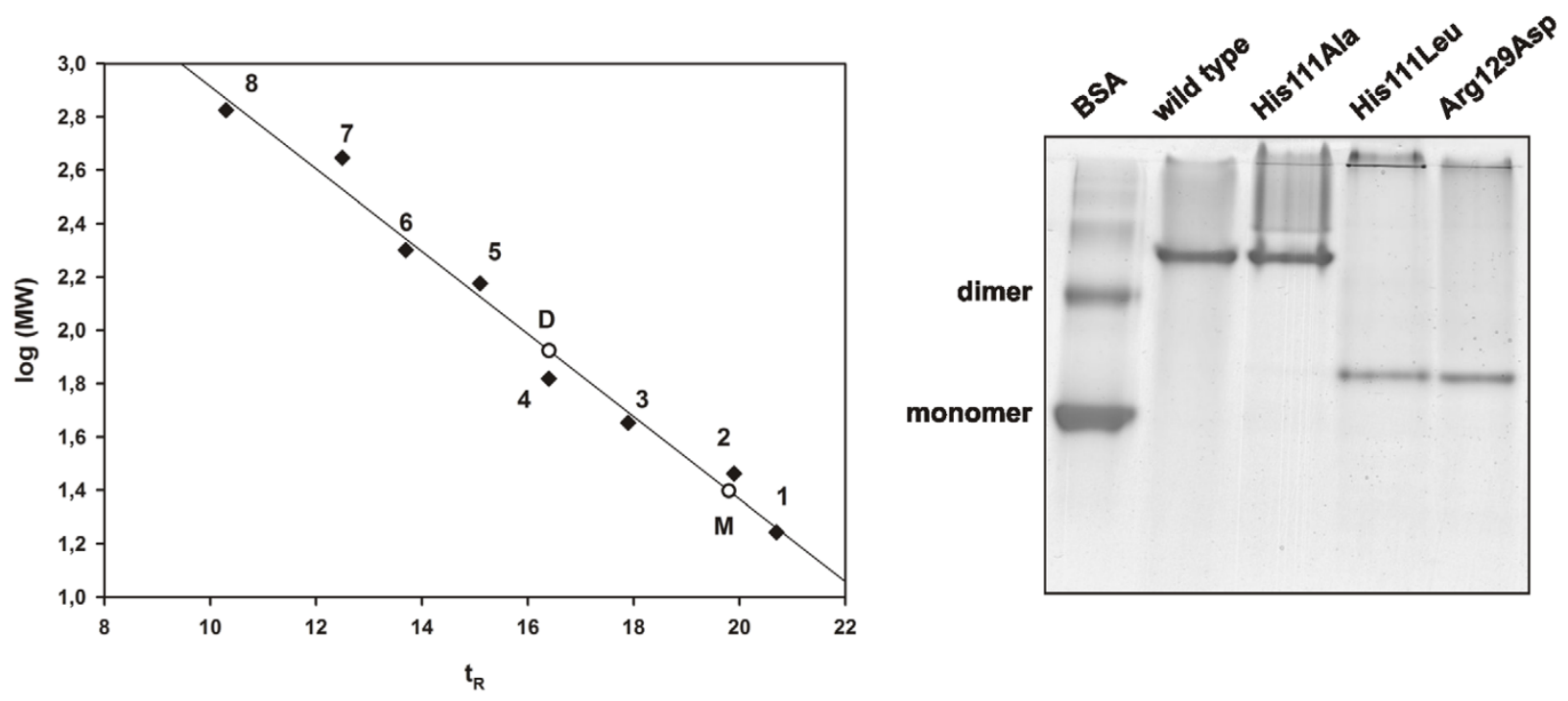

Figure 2

Molecular masses. A) Gel filtration: Native molecular masses were analyzed by gel filtration. The molecular mass standards are represented $(\checkmark)$ by a number from I to 8 , respectively: myoglobin (I $7.5 \mathrm{kDa})$, carbonic anhydrase (29 kDa), ovalbumin (44 $\mathrm{kDa})$, albumin $(66 \mathrm{kDa})$, alcohol dehydrogenase (I50 kDa), $\beta$-amylase (200 kDa), apoferritin (443 kDa) and thyroglobulin (669 $\mathrm{kDa})$. The retention time for the dimers (D) and monomers $(M)$ are also indicated $(O)$. B) Native PAGE: Eight $\mu \mathrm{g}$ of the I7 $\beta$ HSDcl wild-type and mutant proteins were applied to the gel, which was stained with Coomassie Blue. Bovine serum albumin (BSA) was used for comparison.

PAGE. His111Ala-17ß-HSDcl remained a dimer, as with the wild-type protein, while the other two mutations, His111Leu and Arg129Asp, resulted in monomers (Figure 2 ). The dimers eluted at the retention time of albumin with a molecular weight of $66 \mathrm{kDa}$, and the monomers eluted at a time similar to that of carbonic anhydrase (29 $\mathrm{kDa}$ ) (Figure 2a). Differences in mobility of monomeric mutants compared to the dimeric proteins was also observed on the native PAGE (Figure 2b).

\section{Monomer secondary structure is conserved, although the proteins differ in their thermal denaturation characteristics}

The secondary structures of the wild-type and mutant enzymes were analysed through circular dichroism spec- troscopy. This method revealed similar conformations for all the proteins (Figure 3). The thermal denaturation was measured by following the change of the ellipticity at 222 $\mathrm{nm}$ as a function of the temperature. Two behaviours were recognized, that of the wild-type protein and the His111Ala mutant, and that of the two monomeric mutants, His111Leu and Arg129Asp. The melting curves of the wild-type protein and the His111Ala mutant were sigmoidal, revealing a cooperative denaturation. The wild-type protein had a Tm of $44^{\circ} \mathrm{C}$, and the His $111 \mathrm{Ala}$ mutant, of $37^{\circ} \mathrm{C}$. The forms of the melting curves of the other two mutants suggested lower cooperativities of denaturation. The melting points were $48^{\circ} \mathrm{C}$ for the His111Leu mutant and $50^{\circ} \mathrm{C}$ for Arg129Asp (Figure 3)

Table 2: Kinetic constants and $T_{m}$ values for the wild-type and mutant I7 $\beta$-HSDcl

\begin{tabular}{|c|c|c|c|c|c|c|c|c|}
\hline & ${ }^{*} K_{d}^{N A D P+}(\mu \mathrm{M})$ & $K_{M}{ }^{N A D P H}(\mu \mathrm{M})$ & $K_{M}^{N A D P+}(\mu M)$ & $k_{c a t} \operatorname{NADPH}\left(\mathrm{s}^{-1}\right)$ & $k_{\text {cat }}{ }^{\text {NADP+ }}\left(\mathrm{s}^{-1}\right)$ & $k_{c a t} / K_{M, N A D P H}\left(s^{-1} M^{-1}\right)$ & $k_{c a t} / K_{M, N A D P+}\left(s^{-1} M^{-1}\right)$ & $\mathrm{T}_{\mathrm{m}}\left({ }^{\circ} \mathrm{C}\right)$ \\
\hline Wild type & 0.2 & 6.5 & 0.06 & 3.8 & 0.65 & $5.8 \times 10^{5}$ & $1.1 \times 10^{7}$ & 44 \\
\hline His I I IAla & 5.8 & 50.6 & 4.6 & 2.4 & 0.9 & $4.7 \times 10^{4}$ & $1.9 \times 10^{5}$ & 37 \\
\hline His I I ILeu & 19.9 & N.A. & N.A. & N.A. & N.A. & N.A. & N.A. & 48 \\
\hline $\operatorname{Arg} / 29 A s p$ & 12.8 & N.A. & N.A. & N.A. & N.A. & N.A. & N.A. & 50 \\
\hline
\end{tabular}

Kinetic constants for the reduction and oxidation of the substrates 4 -estrene-3, I7-dione and 4-estrene- $17 \beta$-ol-3-one $(100 \mu \mathrm{M})\left(K_{\text {eq }}=2.46 \pm 0.1 \mathrm{I}\right.$ [38]) that were catalyzed by the wild-type and mutant I7 $\beta-$ HSDcl in the presence of the coenzymes NADPH and NADP+ $(100 \mu M)$, at pH 8 and $25^{\circ} \mathrm{C}$. The temperature midpoints $\left(\mathrm{T}_{\mathrm{m}}\right)$ are also given. (* determined by fluorescence titrations; N.A.: no activity detected) 

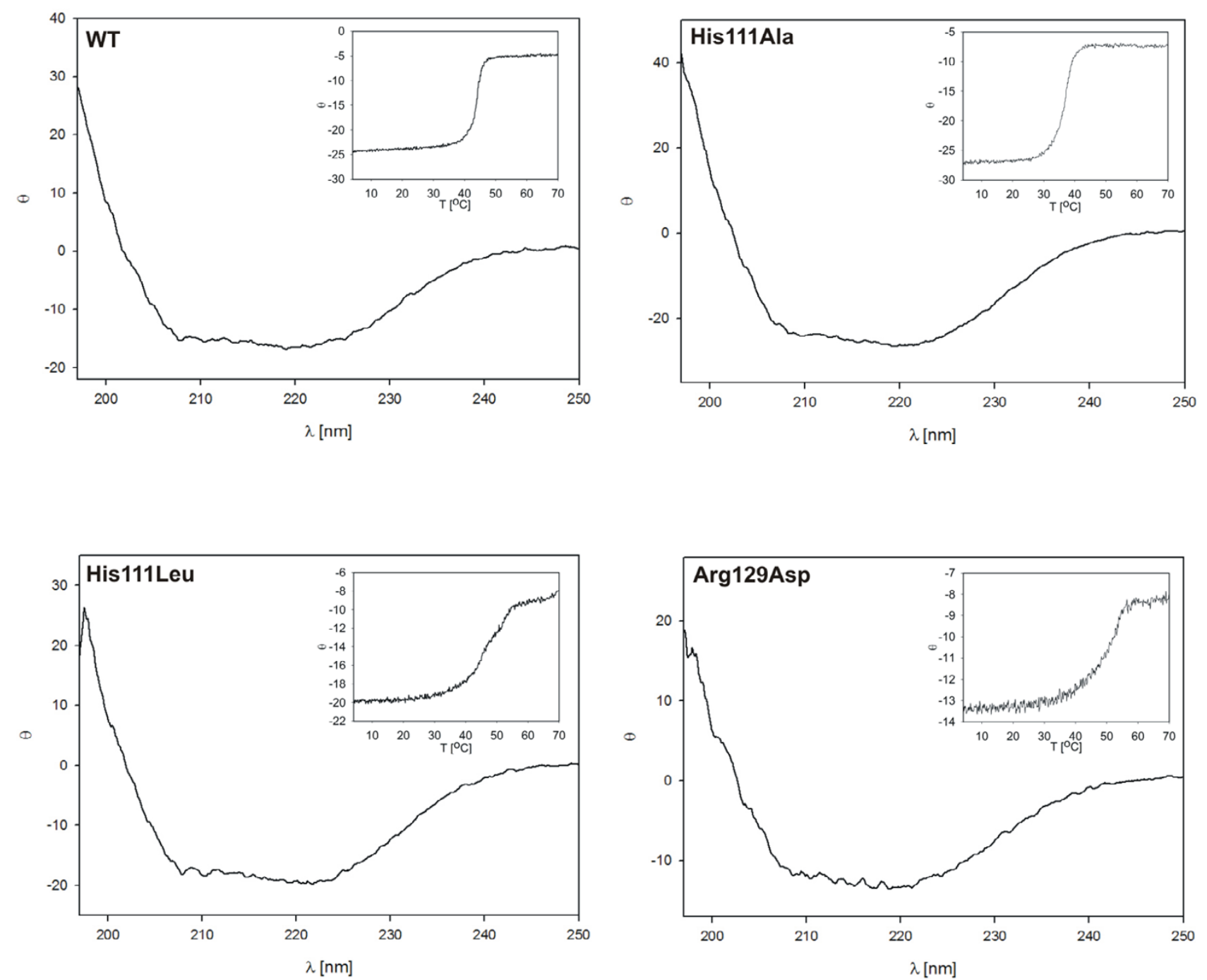

Figure 3

Circular dichroism spectra and thermal denaturation. The circular dichroism spectra were recorded by measuring the ellipticity as a function of wavelength at $0.1 \mathrm{~nm}$ increments between 260 and $197 \mathrm{~nm}$ at $20^{\circ} \mathrm{C}$. The thermal denaturation was determined by measuring the ellipticity as a function of temperature at $0.1^{\circ} \mathrm{C}$ increments between 4 and $70^{\circ} \mathrm{C}$ (inset). The protein concentrations used were approximately $0.2 \mathrm{mg} / \mathrm{ml}$.

(Table 2).

The coenzyme binds to the monomeric mutants

We measured the formation of the binary complexes of $\mathrm{E} \bullet \mathrm{NADP}^{+}$for the wild-type and mutant enzymes. The fluorescence of all of the proteins was quenched by the addition of the coenzyme, but the $K_{d}$ values differed. The $K_{d}$ value for the dimeric mutant His111Ala increased 30fold, and those for the His111Leu and Arg129Asp monomers increased 100-fold and 60-fold, respectively, when compared with the wild-type enzyme (Table 2). These results support the circular dichroism data, suggesting only minor changes in the coenzyme binding site, even in the monomeric enzymes.

The His I I I Leu and Arg I 29Asp mutants are not active on the substrates

The oxidation of 4-estrene-17 $\beta$-ol-3-one and the reduction of 4-estrene-3,17-dione by the wild-type and mutant proteins in the presence of $\mathrm{NADP}^{+}$and NADPH showed enzyme activities for the wild-type protein and for the His111Ala mutant, but no detectable activities for the monomeric His111Leu and Arg129Asp proteins within a 450 s sweep. Although the His111Ala mutant was active, 
its kinetic constants differed from those of the wild-type protein (Table 2). The $K_{M}$ values for both of the coenzymes, $\mathrm{NADP}^{+}$and $\mathrm{NADPH}$, were increased in the His111Ala mutant (77-fold and 8-fold, respectively), while the $k_{\text {cat }}$ values remained similar (Table 2). The specificity constants, $k_{\text {cat }} / K_{m}$, for $\mathrm{NADP}^{+}$and $\mathrm{NADPH}$, were 58 -fold and 12-fold lower, respectively, when compared to those for the wild-type enzyme (Table 2).

Since we could not detect any enzyme activities with the monomeric mutants within the $450 \mathrm{~s}$ sweep, we also tested the enzyme activities by TLC analysis of the products after 24-h incubations of the proteins with 4-estrene$17 \beta$-ol-3-one and $\mathrm{NADP}^{+}$. Again, the wild-type and His111Ala mutant proteins converted this substrate to equilibrium concentrations, while the His111Leu and Arg129Asp mutant proteins did not (data not shown).

\section{Discussion \\ The dimerization of fungal I7 $\beta$-HSD occurs across the $\mathbf{Q}$ - axis}

Among the tens of SDR enzymes for which the threedimensional structures have been resolved, only two are known to be active in solution as monomers (pdb code $1 \mathrm{~N} 5 \mathrm{D}$ and $1 \mathrm{WMA})[6,7]$. We have shown previously, that the wild-type $17 \beta$-HSDcl acts as dimer [10]. In order to influence the formation of this dimer, we substituted two surface amino acids which should not, per se, prevent either the folding or the activity. To avoid possible cooperative phenomena, we prepared mutants with single substitutions, yet we knew that in the dimer the effects would be doubled.

Inspection of the three-dimensional structural model of $17 \beta$-HSDcl [27] supported by our preliminary crystallographic data [28] revealed that His111 from each subunit could form an H-bond with Asp187 from another subunit, while Arg129 could form salt bridge(s) with two negatively charged candidates, Asp121 and Glu117. The importance of these interactions was confirmed directly with three mutations: His111Ala/Leu and Arg129Asp. The His111Ala mutation resulted in dimers, while that of His111Leu prevented the formation of an H-bond as well as the formation of a dimer, most probably because of the steric hindrance introduced by Leu (Figure 2). Substitution of Arg129 by Asp results in electrostatic repulsion between the monomers, and simple calculations revealed that the two abolished salt-bridges result in an approximately $10^{14}$-fold higher dimer dissociation constant $\left(K_{d d}\right)$, thus preventing dimerization. On the other hand, if all of the binding energy were realized in the affinity change caused by two H-bonds, as in the His 111 mutants, only a half of the above change would be expected. It appears that this is still not enough to prevent dimerization (as with His111Ala), unless the steric component is added (as with His111Leu). Since both of the substituted residues are the members of the $\alpha$ E helix, these results strongly suggest that dimerization of fungal $17 \beta$-HSD takes place across the Q-axis.

\section{The denaturation of monomers occurs at higher temperatures}

The results showed that the thermal denaturation of the wild-type protein and the dimeric His111Ala mutant is a cooperative process that involves the disruption of the dimers and the denaturation of the monomers. Compared with the wild-type protein, denaturation of this mutant occurred at a lower temperature (Table 2). The results indicated that the mutation introduced causes a decrease in the thermal stability of the protein, and that the His in position 111 is involved in interactions that stabilize the dimer.

The higher melting temperature of the two monomeric mutants, His111Leu and Arg129Asp, may be associated with a higher stability of the monomers and with a decreased flexibility of their structure in comparison with the dimers. A higher flexibility may be needed to rearrange the conformation after binding of the cofactor, thus enabling proper binding of the substrate, and this may also explain the loss of activity of the His111Leu and Arg129Asp mutants. Additionally, the icebergs of solvent (water) around the exposed hydrophobic groups of the $\alpha \mathrm{E}$ and $\alpha \mathrm{F}$ helices may contribute to the higher Tm. As the temperature is raised, the icebergs melt and their latent heat of fusion contributes significantly to the specific heat capacity $(C p)$ of the denatured state [29].

\section{Dimerization is crucial for enzyme activity}

The substitution of His 111 by Ala at the Q-interface resulted in higher $K_{d}$ values and lower specificity constants $\left(k_{c a t} / K_{M}\right)$ of this dimer when compared with the wild-type enzyme, while the substitution of His 111 by Leu and of Arg129 by Asp resulted in inactive monomers. These results indicate that $\mathrm{H}$-bonds/salt bridges contribute to both the specific dimerization and the enzyme activity. The stability of the Q-interface, which is composed of the $\alpha \mathrm{E}$ and $\alpha \mathrm{F}$ helices, is crucial for enzyme catalysis in the SDR enzymes since two catalytic residues, $\operatorname{Tyr}(167)$ and Lys(171), reside in the interior side of the $\alpha \mathrm{F}$ helix, one catalytic residue, Asn(127), resides in the interior side of the $\alpha \mathrm{E}$ helix, while Ser(153) is positioned in the small $\alpha \mathrm{EF}$ helix, between the $\beta \mathrm{E}$ strand and the $\alpha \mathrm{F}$ helix $[1,30]$. The proper orientation of these catalytically important helices assures the proper orientation (setting, proximity, distance) of the catalytic amino acids to the nicotinamide ring and the substrate, enabling the hydride transfer.

The investigation of another SDR member, glucose dehydrogenase (GlcDH) from Bacillus megaterium IWG3 (pdb 
code 1RWB) [31], supports our hypothesis. GlcDH functions as a tetramer and its crystal structure has revealed weaker hydrophobic interactions and a lack of salt bridges in the Q-interface. For these reasons, the GlcDH tetramer dissociates into inactive monomers at $\mathrm{pH} 9.0$, but reversibly associates into the fully active tetramer at $\mathrm{pH} 6.5$. This is not the case for our fungal enzyme, which is active in the $\mathrm{pH}$ range of 7.0 to 9.0 [32]. Our results and those of others have thus demonstrated that only upon dimerization can the key catalytic residues be brought into the positions that enable the substrate to be converted.

Since both of the mutant monomers show no enzymatic activity despite their conserved secondary structures and the positive coenzyme binding (Table 2), it appears that the enzyme-coenzyme $(\mathrm{E} \bullet \mathrm{NADP}(\mathrm{H}))$ binary complex undergoes conformational changes before the substrate binding can occur. Such a conformational adaptation has previously been proposed for $3 \alpha$-HSD from the SDR superfamily and for several members of the aldo-keto reductase superfamily $[33,34]$. In these proteins, the binding of $\mathrm{NADP}(\mathrm{H})$ involves two events: an initial formation of a loose complex $(\mathrm{E} \bullet \mathrm{NADP}(\mathrm{H}))$, followed by a conformational change in the enzyme structure that leads to a tightly bound complex $\left(E^{*} \bullet N A D P(H)\right)[33,34]$. Our data are in agreement with his hypothesis.

\section{Dimerization via the Q-axis is not possible in $3 \alpha-H S D / C R$, PTCR and CBRI}

On comparing the crystal structures of dimeric and tetrameric SDRs with those of $3 \alpha \mathrm{HSD} / \mathrm{CR}$, where dimerization takes place via a P-axis interface $[4,5]$, and of PTCR and CBR1, the only monomeric enzyme structures of the SDR superfamily $[6,7]$, it becomes evident that in all three structures, interactions across the Q-axis are blocked by the presence of a predominantly $\alpha$-helical subdomain. In these three proteins, this 28,41 or 41 amino-acid insertion into the classical Rossman-fold motif between strand $\beta \mathrm{E}$ and helix $\alpha \mathrm{F}$, respectively, prevents the formation of a four-helix bundle, while at the same time it masks, and in this manner stabilizes, the $\alpha \mathrm{E}$ and $\alpha \mathrm{F}$ helices. To determine whether the lack of this subdomain leads to the formation of a homotetramer, a redesign of this interface was recently performed in the dimeric $3 \alpha-\mathrm{HSD} / \mathrm{CR}$, and further enzymatic characterization is currently in progress [34]. This insertion is not present in other SDRs that can stabilize the $\alpha \mathrm{E}$ and $\alpha \mathrm{F}$ helices by dimerization via the $\mathrm{Q}$ axis interface. Therefore, again, dimerization appears to be crucial for the stability of the $\alpha \mathrm{E}$ and $\alpha \mathrm{F}$ helices in the fungal $17 \beta-H S D$ as well as in other SDR proteins, except $3 \alpha-$ HSD/CR, PTCR and CBR1.

\section{Selective prevention of dimerization may enable the development of a new type of drug}

A detailed understanding of the importance of specific residues for dimerization should enable the design of compounds that can prevent the dimerization and thus serve as a new type of drug. This proposal is supported by the finding that the residues involved in subunit interactions differ considerably between the enzymes. Recently, Caffrey et al. (2004) examined the difference in conservation between the protein-protein interfaces and the rest of the protein surfaces for a set of 64 proteins from different protein superfamilies [36]. A surface-patch analysis showed that this interface is rarely significantly more conserved than other surface patches [36]. Although almost all of the SDR proteins span across the Q-axis interface, the residues involved in the dimerization are not conserved. Subunit interactions at the $\alpha \mathrm{E}-\alpha \mathrm{E}$ contact regions were compared in 6 members of the SDR superfamily (GlcDH, mouse lung carbonyl reductase, Streptomyces hydrogenans $3 \alpha, 20 \beta$ HSD, Pseudomonas sp. cis-biphenyl-2,3-dihydrodiol-2,3dehydrogenase, Escherichia coli $7 \alpha-\mathrm{HSD}$, Magnaporthe grisea 3HNR) [31], whereby different modes of subunit interactions were shown in these proteins. Therefore, the concept that the selective prevention of dimerization in the SDR proteins will lead to the development of a new type of inhibitors is reasonable.

\section{Conclusion}

Fungal $17 \beta-H S D$ is a dimeric member of the SDR superfamily. We have shown by site-directed mutagenesis and structure/function analysis that the dimerization takes place across the $\mathrm{Q}$-axis and involves the $\alpha \mathrm{E}$ and $\alpha \mathrm{F}$ helices of both subunits. Neighbouring subunits are connected through hydrophobic interactions, $\mathrm{H}$-bonds and salt bridges involving amino-acid residues His111 and Arg129. The substitution of these amino acid residues leads to inactive monomers with conserved secondary structures that are still able to bind the coenzyme. Our results indicate that the stability of the $\alpha \mathrm{E}$ and $\alpha \mathrm{F}$ helices that include catalytic amino acid residues is crucial for enzyme activity. Although oligomerization of the SDR proteins has already been studied in Drosophila alcohol dehydrogenase and human $17 \beta$-HSD type 1 , our study is the first that has prepared monomeric mutants in sufficient quantities and qualities for structure/function analysis.

\section{Methods}

\section{Preparation of mutant proteins}

The mutant proteins were prepared using the QuickChange Site-Directed Mutagenesis Kit (Stratagene) and the pGex-17 $\beta$-HSDcl expression vector [10]. The following primers were used (only mutagenic forward primers are shown; the mutations introduced are underlined): 
$\operatorname{Arg} 129 A s p$

for: 5'-GCCTCAACACCGACGGCCAGTTCTTCG-3'

His111Ala

for: 5'-CGTGAGCTTCGGCGCCCTCAAGGACGTG-3'

His111Leu

for: 5'-CGTGAGCTTCGGCCTCCTCAAGGACGTG-3'

The fidelity of the constructs was confirmed by dideoxy sequencing.

\section{Expression and purification of proteins}

All of the proteins were expressed as GST-fusion proteins in the JM107 E. coli strain and purified by affinity chromatography on Glutathione Sepharose followed by cleavage with thrombin, as described previously [10].

\section{SDS PAGE}

Homogeneity of the proteins was checked by SDS-PAGE. Samples $(4 \mu \mathrm{g})$ were denatured in Laemmli sample buffer (5 min at $90^{\circ} \mathrm{C}$ ), applied to $12 \%$ acrylamide gels, and visualized by Coomassie Blue staining.

\section{Estimations of molecular mass Gel filtration}

The molecular masses were determined by gel filtration on BioCad Sprint FPLC. The mobile phase was $100 \mathrm{mM}$ phosphate buffer $\left(\mathrm{Na}_{2} \mathrm{HPO}_{4} / \mathrm{NaH}_{2} \mathrm{PO}_{4}\right)$ with $150 \mathrm{mM}$ $\mathrm{NaCl}, \mathrm{pH}$ 7.0. Approximately $40 \mu \mathrm{g}$ of protein in $100 \mu \mathrm{l}$ was injected onto a TSK G4000 SWxl column (7.5 mm ID $\times 60 \mathrm{~cm}$ ) and analyzed at a $1.0 \mathrm{ml} / \mathrm{min}$ flow rate. Elution of the proteins was followed at $280 \mathrm{~nm}$. The void volume of the column was determined with blue dextran. The calibration standards were: myoglobin (horse heart) (17.5 $\mathrm{kDa})$, carbonic anhydrase (bovine erythrocyte) (29 kDa), ovalbumin (albumin from hen egg white) (44 kDa), albumin (bovine serum) $(66 \mathrm{kDa})$, alcohol deydrogenase (yeast) $(150 \mathrm{kDa}), \beta$-amylase (sweet potato) $(200 \mathrm{kDa})$, apoferritin (horse spleen) (443 kDa) and thyroglobulin (bovine) (669 kDa).

\section{Non-denaturing PAGE}

Eight $\mu \mathrm{g}$ of protein were run on $9 \%$ acrylamide gels, as described previously [37]. Following electrophoresis at $150 \mathrm{~V}$, the proteins were stained by Coomassie Blue.

\section{Secondary structure determinations}

Preservation of the secondary structures was followed by circular dichroism spectroscopy (JASCO Corp. J-715 spectropolarimeter; PFD-350S temperature controller; maintained by J-700 software package). The spectra were recorded at $20^{\circ} \mathrm{C}$ at $0.1 \mathrm{~nm}$ increments between 250 and $197 \mathrm{~nm}$ using $0.1 \mathrm{~cm}$ path length cuvettes. The scanning speed was $50 \mathrm{~nm} / \mathrm{min}$, the response time $1 \mathrm{sec}$, and an average of 4 scans was recorded. The protein concentrations were approximately $0.2 \mathrm{mg} / \mathrm{ml}$, in PBS ( $\mathrm{pH} 7.3$ ).

\section{Thermal denaturation of proteins}

Ellipticity was measured at $222 \mathrm{~nm}$ at $0.1^{\circ} \mathrm{C}$ increments between 4 and $70^{\circ} \mathrm{C}$. The temperature was raised at $30^{\circ} \mathrm{C} /$ $\mathrm{h}$, the response time was $16 \mathrm{sec}$, and the bandwidth was 1 $\mathrm{nm}$. At the end of each experiment the temperature was decreased to $4{ }^{\circ} \mathrm{C}$ to verify the reversibility of the denaturation.

\section{Coenzyme binding}

To determine coenzyme binding constants, we measured the changes in the intrinsic enzyme fluorescence upon the incremental addition of coenzymes $(0-30 \mu \mathrm{M})$ on a Cary Eclipse fluorescence spectrophotometer (Varian). To ensure that the volume of coenzyme added was not more than $3 \%$, three stock solutions of the coenzyme were prepared $-15 \mathrm{mM}, 1.5 \mathrm{mM}$ and $150 \mu \mathrm{M}$. A $4 \times 10-\mathrm{mm}$ cuvette with a magnetic stirrer was used, and each $800 \mu \mathrm{l}$ sample contained $1 \mu \mathrm{M}$ protein in $100 \mathrm{mM}$ phosphate buffer, $\mathrm{pH} 8.0$ at $25^{\circ} \mathrm{C}$. The samples were excitated at 290 $\mathrm{nm}$ with the fluorescence emission scanned at $335 \mathrm{~nm}$ and with the excitation and emission band-passes set at 5 $\mathrm{nm}$. Single or double hyperbolic equations were fitted to the data to estimate the corresponding dissociation constants for the wild-type and mutant forms of 17ß-HSDcl.

\section{Enzyme activities}

The interconversion between 4-estrene-3,17-dione and 4estrene-17 $\beta$-ol-3-one in the presence of NADPH or $\mathrm{NADP}^{+}$catalyzed by the wild-type and mutated enzymes was followed photometrically at $340 \mathrm{~nm}$, in $100 \mathrm{mM}$ phosphate buffer, $\mathrm{pH} 8.0$ at $25^{\circ} \mathrm{C}$. In all of the experiments, $1 \%$ DMF was present, to enhance substrate solubility. The time course of absorbance at $340 \mathrm{~nm}$ was measured for $450 \mathrm{~s}$. The progress curves were analyzed according to the procedure described previously [38].

\section{Thin-layer chromatography (TLC)}

The wild-type and mutant proteins $(0.5 \mu \mathrm{M})$ were incubated with 4-estrene-17 $\beta$-ol-3-one $(100 \mu \mathrm{M})$ in the presence of $\mathrm{NADP}^{+}(500 \mu \mathrm{M})$ in $100 \mathrm{mM}$ phosphate buffer, $\mathrm{pH}$ 8.0, for $24 \mathrm{~h}$ at room temperature. The steroids were extracted with chloroform and analyzed by TLC as described previously [37].

\section{List of abbreviations}

$17 \beta$-HSDcl, $17 \beta$-hydroxysteroid dehydrogenase from $C$. lunatus; 3HNR, 1,3,8-trihydroxynaphthalene reductase; 4HNR, 1,3,6,8-tetrahydroxynaphthalene reductase; CBR1, human carbonyl reductase; $C R$, carbonyl reductase; 
GlcDH, glucose dehydrogenase; GST, glutathione S-transferase; HSD, hydroxysteroid dehydrogenase; PTCR, porcine testicular carbonyl reductase; SDR, short-chain dehydrogenase/reductase

\section{Authors' contributions}

KK carried out the bulk of the experimental work presented herein (site-directed mutagenesis, enzyme purifications, fluorescence measurements, enzymatic assays). DD was integral to the secondary structure determinations of the enzymes, and the thermal denaturation and gel filtration. JS analyzed the progress and titration curves, determined the rates and kinetic constants, and participated in the interpretation of the results. TLR and JA participated in the conception of the study, in the design of the study, and in the writing and revising of the manuscript. All of the authors have read and approved the final manuscript.

\section{Acknowledgements}

The work was supported by Ministry of Education, Science and Sport of Slovenia and by a FEBS short-term fellowship and WFS grant to K.K. We thank Dr. Karin Pritsch for use of the fluorescence spectrophotometer (GSF, Institute of Soil Ecology, Neuherberg, Germany) and Prof. Dr. Luis Moroder, Elisabeth Weyher (Max-Planck Institute of Biochemistry, Martinsried, Germany) and Dr. Eva Žerovnik (»Jožef Stefan« Institute, Ljubljana, Slovenia) for use of the circular dichroism spectropolarimeter. We are grateful to Dr. Alberto Cassetta and Prof. Dr. Doriano Lamba for providing the preliminary crystallographic data.

\section{References}

I. Oppermann U, Filling C, Hult M, Shafgat N, Wu X, Lindh M, Shafqat J, Nordling E, Kallberg Y, Persson B, Jörnvall H: Short-chain dehydrogenases/reductases (SDR): the 2002 update. Chem Biol Interact 2003, I 43-I 44:247-253.

2. Krook M, Ghosh D, Duax W, Jörnvall H: Three-dimensional model of NAD+-dependent I5-hydroxyprostaglandin dehydrogenase and relationships to the NADP+-dependent enzyme (carbonyl reductase). FEBS lett | 993, 322: | 39- I 42

3. Penning TM: Molecular endocrinology of hydroxysteroid dehydrogenases. Endocr Rev 1997, 18:281-305.

4. Grimm C, Maser E, Möbus E, Klebe G, Reuter K, Ficner R: The crystal structure of $3 \alpha$-hydroxysteroid dehydrogenase/carbonyl reductase from Comamonas testosteroni shows a novel oligomerization pattern within the short chain dehydrogenase/ reductase family. J Biol Chem 2000, 275:41333-4I339.

5. Maser E, Xiong G, Grimm C, Ficner R, Reuter K: 3 $\alpha$-Hydroxysteroid dehydrogenase/carbonyl reductase from Comamonas testosteroni: biological significance, three-dimensional structure and gene regulation. Chem Biol Interact 200I, 130132:707-722.

6. Ghosh D, Sawicki M, Pletnev V, Erman M, Ohno S, Nakajin S, Duax W: Porcine carbonyl reductase. Structural basis for a functional monomer in short chain dehydrogenases/reductases. J Biol Chem 200I, 276: I8457-18463.

7. Tanaka M, Bateman R, Rauh D, Vaisberg E, Ramachandani S, Zhang C, Hansen KC, Burlingame AL, Trautman JK, Shokat KM, Adams CL: An unbiased cell morphology-based screen for new, biologically active small molecules. PLOS Biol 2005, 3:764-776.

8. Kallberg Y, Oppermann U, Joernvall H, Persson B: Short-chain dehydrogenase/reductase (SDR) relationships: a large family with eight clusters common to human, animal, and plant genomes. Protein Science 2002, I I:636-64I.

9. Lanišnik Rižner T, Žakelj-Mavrič M, Plemenitaš A, Zorko M: Purification and characterization of $17 \beta$-hydroxysteroid dehydrogenase from the filamentous fungus Cochliobolus lunatus. J Steroid Biochem Mol Biol 1996, 59:205-214.
10. Lanišnik Rižner T, Moeller G, Thole HH, Žakelj-Mavrič M, Adamski ]: A novel 17 $\beta$-hydroxysteroid dehydrogenase in the fungus Cochliobolus lunatus: new insights into the evolution of steroid-hormone signalling. Biochem J 1999, 337:425-43|.

II. Lanišnik Rižner T, Stojan J, Adamski J: 17/3-hydroxysteroid dehydrogenase from the fungus Cochliobolus lunatus: structural and functional aspects. Chem Biol Interact 200I, 130132:793-803.

12. Andersson S, Jordan D, Schneider G, Lundqvist $Y$ : Crystal structure of the ternary complex of I,3,8-trihydroxy-naphthalene reductase from Magnaporthe grisea with NADPH and an active-site inhibitor. Structure 1996, 4:1161-II70.

13. Thompson JE, Basarab GS, Andersson A, Lundqvist Y, Jordan DB: Trihydroxynaphthalene reductase from Magnaporthe grisea: Realization of an active center inhibitor and elucidation of the kinetic mechanism. Biochemistry 1997, 36: 1852-1860.

14. Thompson JE, Fahnestock S, Farral L, Liao D, Valent B, Jordan DB: The second naphthol reductase of fungal melanin biosynthesis in Magnaporthe grisea. J Biol Chem 2000, 275:34867-34872.

15. Liao D, Thompson JE, Fahnestock S, Valent B, Jordan DB: A structural account of substrate and inhibitor specificity differences between two naphthol reductases. Biochemistry 200I, 40:8696-8704.

16. Jordan DJ, Basarab GS, Liao D, Johnson WMP, Winzenberg KN, Winkler DA: Structure-based design of inhibitors of the rice blast fungal enzyme trihydroxynaphthalene reductase. J Mol Graph Model 200I, 19:434-447.

17. Fomitcheva J, Baker ME, Anderson E, Lee GY, Aziz N: Characterization of Ke6, a new I7 $\beta$-hydroxysteroid dehydrogenase, and its expression in gonadal tissues. J Biol Chem 1998, 273:22664-2267I.

18. Li A, Tedde R, Krozowski ZS, Pala A, Li KX, Shackleton CH, Mantero F, Palermo M, Stewart PM: Molecular basis for hypertension in the "type II variant" of apparent mineralocorticoid excess. Am J Hum Genet 1998, 63:370-379.

19. He XZ, Merz G, Mehta P, Schultz H, Yang S-Y: Human brain shortchain L-3-hydroxyacyl coenzyme $A$ dehydrogenase is a single domain multifunctional enzyme. J Biol Chem 1999, 274: I50|4-I50|9.

20. Lin SX, Han Q, Azzi A, Zhu D, Gangloff A, Campbell RL: 3D-structure of human estrogenic I7 $\beta$-HSDI: binding with various steroids. I Steroid Biochem Mol Biol 2000, 73: 183.

2I. Masuzaki H, Peterson J, Shinyama H, Morton NM, Mullins JJ, Seckl JR, Flier JS: A transgenic model of visceral obesity and the metabolic syndrome. Science 200 I, 294:207/-2072.

22. Mindnich R, Moller G, Adamski J: The role of I7 $\beta$-hydroxysteroid dehydrogenases. Mol Cell Endocrinol 2004, 2 1 8:7-20.

23. Vihko P, Harkonen P, Soronen P, Torn S, Herrala A, Kurkela R, Pulkka $A$, Oduwole $O$, Isomaa $V: 17 \beta$-hydroxysteroid dehydrogenasestheir role in pathophysiology. Mol Cell Endocrinol 2004, 215:83-88.

24. Hopkins AL, Groom CR: The druggable genome. Nat Rev Drug Discov 2002, I:727-730.

25. Chenevert SW, Fossett NG, Chang SH, Tsigelny I, Baker ME, Lee WR: Characterization of structural and functional properties of human 17 $\beta$-hydroxysteroid dehydrogenase type I using recombinant enzymes and site-directed mutagenesis. Biochem J 1995, 308:419-423.

26. Puranen $T$, Poutanen M, Ghosh D, Vihko P, Vihko R: Amino acids important in enzyme activity and dimer stability for Drosophila alcohol dehydrogenase. Mol Endocrinol 1996, I I:77-86.

27. Lanišnik Rižner T, Adamski J, Stojan J: I7 $\beta$-hydroxysteroid dehydrogenase from Cochliobolus lunatus: model structure and substrate specificity. Archiv Biochem Biophys 2000, 384:255-262.

28. Cassetta A, Büdefeld T, Lanišnik Rižner T, Kristan K, Stojan J, Lamba $D$ : Crystallization, $\mathbf{X}$-ray diffraction analysis and phasing of 17 $\beta$-hydroxysteroid dehydrogenase from the fungus Cochliobolus lunatus. Acta Crystal 2005, F6 I:1032-1034.

29. Fersht A: A guide to enzyme catalysis and protein folding. In Structure and mechanism in protein science USA: WH Freeman and Company; 1999:508-539.

30. Filling C, Berndt KD, Benach J, Knapp S, Prozorovski T, Nordling E, Ladenstein $R$, Jörnvall $H$, Oppermann $U$ : Critical residues for structure and catalysis in short-chain dehydrogenases/ reductases. I Biol Chem 2002, 277:25677-25684 
31. Yamamoto K, Kurisu G, Kusunoki M, Tabata S, Urabe I, Osaki S: Crystal structure of glucose dehydrogenase from Bacillus megaterium IWG3 at I.7 A resolution. J Biochem (Tokyo) 200I, 129:303-3/2.

32. Lanišnik Rižner T, Stojan J, Adamski J: Searching for the physiological function of $17 \beta$-hydroxysteroid dehydrogenase from the fungus Cochliobolus lunatus: studies of substrate specificity and expression analysis. Mol Cell Endocrinol 200I, I 7 I:193-198.

33. Ueda S, Oda M, Imamura S, Ohnishi M: Transient-phase kinetic studies on the nucleotide binding to $3 \alpha$-hydroxysteroid dehydrogenase from Pseudomonas sp. B-083 I using fluorescence stopped-flow procedures. Eur J Biochem 2004, 271: I 774- 1780.

34. Ratnam K, Ma H, Penning TM: The arginine 276 anchor for NADP(H) dictates fluorescence kinetic transients in $3 \alpha-$ hydroxysteroid dehydrogenase, a representative aldo-keto reductase. Biochemistry 1999, 38:7856-7864.

35. Hoffmann F, Sotriffer C, Evers A, Xiong G, Maser E: Structural aspects of oligomerization in $3 \alpha$-hydroxysteroid dehydrogenase/carbonyl reductase from Comamonas testosteroni: New approaches for efficient protein design. In Enzymology and Molecular Biology of Carbonyl Metabolism 12 Edited by: Weiner H, Plapp B, Lindahl R, Maser E. West Lafayette, Indiana: Purdue Univ Press; 2005:308-3।4.

36. Caffrey DR, Somaroo S, Hughes JD, Mintseris J, Huang ES: Are protein-protein interfaces more conserved in sequence than the rest of the protein surface? Protein Science 2004, I3:190-202.

37. Kristan K, Lanišnik Rižner T, Stojan J, Gerber JK, Kremmer E, Adamski J: Significance of individual amino acid residues for coenzyme and substrate specificity of $17 \beta$-hydroxysteroid dehydrogenase from the fungus Cochliobolus lunatus. Chem Biol Interact 2003, I43-I44:493-50I.

38. Kristan K, Stojan J, Möller G, Adamski J, Lanišnik Rižner T: Coenzyme specificity in fungal $17 \beta$-hydroxysteroid dehydrogenase. Mol Cell Endocrinol 2005, 24I:80-87.

Publish with Bio Med Central and every scientist can read your work free of charge

"BioMed Central will be the most significant development for disseminating the results of biomedical research in our lifetime. "

Sir Paul Nurse, Cancer Research UK

Your research papers will be:

- available free of charge to the entire biomedical community

- peer reviewed and published immediately upon acceptance

- cited in PubMed and archived on PubMed Central

- yours - you keep the copyright

Submit your manuscript here:

http://www.biomedcentral.com/info/publishing_adv.asp
BiolMedcentral 